1 Universidade Federal de São Paulo (Unifesp), Departamento de Gestão e Cuidados em Saúde Santos (SP), Brasil.

fernanda.frutuoso@unifesp.br

2 Universidade Federal de São Paulo (Unifesp),

Departamento de Políticas

Públicas e Saúde Coletiva -

Santos (SP), Brasil.

rosildamendes@terra.com.br

${ }^{3}$ Secretaria Nacional de Políticas sobre Drogas

(Senad), Brasil.

karina_to@hotmail.com

4 Universidade Federal de São Paulo (Unifesp), Departamento de Políticas Públicas e Saúde Coletiva Santos (SP), Brasil.

carobert3@hotmail.com

\section{Gestão local de saúde em território de vulnerabilidade: motivações e racionalidades}

\author{
Local management of health in territory of vulnerability: motivations \\ and rationalities
}

Maria Fernanda Petroli Frutuoso', Rosilda Mendes $\mathbf{2}$, Karina Rodrigues Matavelli Rosa ${ }^{\mathbf{3}}$, Carlos Roberto de Castro e Silva ${ }^{4}$

RESUMO Os contrastes das cidades trazem questões à produção da saúde e à gestão do cuidado em territórios de vulnerabilidade. Estudou-se a percepção de gestores e profissionais em relação ao processo de trabalho em saúde, suas motivações e racionalidades, em um território atendido pela Estratégia Saúde da Família. Os profissionais sentem-se motivados pela filantropia e pela vocação profissional a partir da percepção de que a Atenção Básica compreende práticas com menor densidade tecnológica. Ações emergenciais com enfoque assistencialista reforçam o modelo de cuidado, com predominância de ações de tratamento diante da naturalização dos problemas de saúde atrelados à pobreza extrema da região.

PALAVRAS-CHAVE Atenção Primária à Saúde; Assistência à saúde; Vulnerabilidade social.

ABSTRACT Contrasts of cities bring issues to health production and care management in areas of vulnerability. It was studied the perception of managers and professionals in relation to the work process in health, their motivations and rationalities, in a territory assisted by the Family Health Strategy. Professionals feel motivated by philanthropy and by a sense of professional vocation from the perception that primary care incorporates practices with lower technological density. Emergency actions with supporting approach reinforce a care model with predominance of treatment actions before the naturalization of health problems related to the extreme poverty of the region.

KEYWORDS Primary Health Care; Delivery of health care; Social Vulnerability. 


\section{Introdução}

No debate contemporâneo em torno dos problemas sociais manifestados na cidade, evidenciam-se novos e velhos temas: a globalização financeira; a urbanização e a metropolização crescentes; a existência de segmentos da população afastados do mundo do capitalismo globalizado; a segregação; a desigualdade; a exclusão; e a pobreza. Igualmente, tem-se formulado a ideia de que as cidades podem ser repensadas para transformarem a realidade socioespacial, tornando-se melhores lugares para se viver. Esta premissa reconhece, portanto, as forças e tensões que permeiam a tessitura das cidades, e aponta para os grandes desafios colocados às mudanças e às transformações (KOGA, 2003; VERAS, 2010; SOUZA, 2010).

Bauman (2009), refletindo sobre os espaços urbanos de nosso tempo, destaca a experiência ambivalente em que se transformou o viver na cidade. Segundo o autor, "os mesmos aspectos da vida na cidade que atraem, ao mesmo tempo ou alternadamente, repelem". A cidade é fonte de medo e exerce, simultaneamente, forte "poder de sedução" (BAUMAN, 2009, P. 46-47).

Esses contrastes e condições trazem, sem dúvida, uma série de questões à produção da saúde e à gestão do cuidado em territórios de atuação da Estratégia Saúde da Família (ESF). A saúde é produzida nos espaços da vida, onde as pessoas estabelecem relações. Trata-se de priorizar os aspectos políticos desse território, e a existência de contextos afetivos e de significação no cotidiano das pessoas, o que interfere na forma de reconstruir as práticas de saúde. Essa dupla significação traz inúmeros desafios e parece ser um profícuo horizonte à produção social da saúde (GONZÁLEZ-REY; MORI, 2011).

Sob essa perspectiva, torna-se particularmente desafiadora a compreensão do contexto, da dinâmica social e da organização de serviços de saúde em municípios como Cubatão (SP), que cresceu com a expansão industrial e petroquímica do País nos anos de 1950, e teve sua história associada a constantes ameaças de poluição de todas as ordens, reforçando sua imagem de cidade doente. $\mathrm{O}$ intenso processo de urbanização desordenado, típico da modernização apressada e sem preocupação social, esgarçou os limites dos bairros periféricos e levou os trabalhadores locais - principalmente, migrantes nordestinos - a ocuparem uma pequena parte das planícies, já ocupadas por indústrias, mangues aterrados e palafitas.

Há de se destacar, ainda, o grave problema de infraestrutura básica em alguns bairros, especialmente os que possuem grande concentração de palafitas localizadas sobre o mangue do Rio Casqueiro, com ligações de luz clandestinas e esgoto a céu aberto. $\mathrm{Na}$ maior parte das vezes, os dejetos e o lixo são depositados diretamente na maré, passando ao lado ou embaixo das moradias. Assim, por tratar-se de uma área de ocupação irregular, o governo não se compromete a fazer melhorias de infraestrutura no local.

Não é sem razão que, nas discussões e reflexões dos profissionais de saúde da Unidade de Saúde da Família (USF) da Vila dos Pescadores, também situada em Cubatão (SP), de que trata especificamente este artigo, seja retratado um complexo contexto de vida local. Eles reforçam, em seus discursos, as fragilidades e os problemas de um território marcado por desigualdades sociais, e, ao mesmo tempo, valorizam o cotidiano de trabalho com as famílias, a relação com os vizinhos, os laços de amizade, os encontros, as festas, a cooperação.

Se pensarmos na produção social da saúde, nos aproximamos do modelo teórico-metodológico dos Determinantes Sociais da Saúde (DSS), discutido recentemente por Solar e Irwin (2010), que procura esquematizar a trama de relações entre os diversos fatores determinantes do processo saúde-doença. Este modelo apresenta claramente a noção de que tal processo é intrinsecamente histórico e determinado por condições estruturais e 
conjunturais. Há, por um lado, uma explicitação da importância dos contextos socioeconômicos e políticos, e da atuação na macropolítica de abrangência populacional. Por outro lado, são destacados outros componentes como fundamentais para a promoção e a proteção da saúde individual e coletiva: os laços de coesão social, as relações de solidariedade e confiança entre pessoas e grupos. Nestes, são incluídas políticas que buscam estabelecer redes de apoio local e fortalecer a organização e a participação das pessoas e das comunidades - especialmente, dos grupos vulneráveis - em ações coletivas para a melhoria de suas condições de vida e saúde (BUSS; PELLEGRINI, 2007; SHEIKHATTARI; KAMANGAR, 2010; OMS, 2011).

Ao atuar sobre uma temática específica naquele território em particular, podemos nos perguntar: Seria possível realizar ações de cuidado à saúde voltados a construir uma governança local adequada à implementação de ações sobre os determinantes sociais? Quais seriam os aspectos a serem considerados nessa abordagem? Poderíamos buscar uma diminuição dos diferenciais de exposição a riscos, tendo como alvos, por exemplo, os grupos que vivem em condições de habitação insalubres ou estão expostos à insegurança alimentar e nutricional que leva a deficiências nutricionais? Se quisermos enfrentar diferenciais de vulnerabilidade, quais seriam as intervenções mais efetivas para este fim? "Trata-se, assim, de um amplo processo social de construção de condições de vida, que tem, certamente, objetivos ligados ao setor saúde, mas não se resume a ele" (FRAGA ET AL., 2013, P. 31).

Este artigo apresenta parte dos resultados de uma investigação que analisou as práticas dos Agentes Comunitários de Saúde (ACS), a partir do contexto sócio histórico de uma USF. Focalizamos aqui a percepção dos gestores e profissionais em relação ao processo de trabalho em saúde - suas motivações e racionalidades -, em um território de grande vulnerabilidade, localizado nos manguezais do Município de Cubatão (SP).

\section{Percurso metodológico}

Este estudo de caráter qualitativo propiciou avanços na discussão da interface entre a saúde coletiva e as ciências humanas, com ênfase na psicologia social e comunitária, e na antropologia aplicada em espaço de Atenção Básica ( $\mathrm{AB})$, em território de alta vulnerabilidade social.

Foram realizadas entrevistas semiestruturadas com quatro gestores $(\mathrm{G})$ selecionados de acordo com o lugar que ocupam na gestão da saúde do Município de Cubatão (SP), e com três profissionais (PS) da USF.

Quanto à análise dos dados, optou-se pela Hermenêutica de Profundidade (HP), proposta por John Thompson (1995), que propicia a análise de fenômenos culturais, contextualizados sócio historicamente, e propõe uma metodologia que privilegia os fenômenos culturais e suas formas simbólicas, dentro de contextos estruturados. Thompson (1995, P. 359) sugere, como diz a tradição da hermenêutica, que o campo-objeto das ciências sociais se preocupa com um terreno já pré-interpretado. As pessoas vivem em um mundo construído por significados, buscando, em seu cotidiano, compreender e dar sentido às suas vidas. E estes significados são reinterpretados de acordo com condições sócio históricas, ou seja, este campo-objeto também é um campo-sujeito. Além disto, a hermenêutica também lembra que o campo-objeto inclui, inevitavelmente, os sujeitos, pois estes são "capazes de compreender, refletir e de agir fundamentados nessa compreensão e reflexão".

Este referencial compreende três fases ou procedimentos, que foram adotados no presente estudo. São eles: a) Análise sócio histórica, que buscou contextualizar as formas simbólicas produzidas dentro de determinadas condições sócio históricas - no caso, um território de alta vulnerabilidade social; b) Análise formal ou discursiva, que teve o intuito de proceder a uma análise da organização interna das formas simbólicas, 
buscando padrões e relações internas no discurso dos sujeitos em situações concretas de existência. Tal análise foi precedida de uma ordenação de dados, que incluiu a transcrição do material gravado, a leitura e uma releitura exaustiva das entrevistas, e a organização dos relatos em determinada ordem (o que já supõe um início de classificação). Essa fase foi realizada com recursos da análise de discurso, a partir de tópicos que auxiliaram a construção de tabelas referentes a cada um dos entrevistados: identificação, categorias empíricas (incluindo subcategorias), trechos das falas (corpus), impressões (análise discursiva) e interpretação preliminar; e c) A interpretação, que buscou articular as duas fases anteriores, visou a uma reinterpretação de situações e temas. Este processo propõe o esforço de dar novas interpretações para formas simbólicas que já possuem pré-interpretações, pois o objeto-domínio que se pretende compreender já é compreendido pelos sujeitos que fazem parte do mundo sócio histórico. Nesta perspectiva, a interpretação representa uma maior elasticidade da análise das formas simbólicas produzidas pelos sujeitos da pesquisa, dando destaque para suas experiências singulares. A interpretação consistiu, portanto, no exercício de transitar entre o concreto e o abstrato, entre o teórico e o empírico, buscando aproximar-se da realidade e interpretá-la, atribuindo-lhe significados e sentidos.

Todos os procedimentos éticos foram cumpridos conforme orientações do Conselho de Ética em Pesquisa da Universidade (Parecer $n^{\circ} 103.202$, de 21/09/2012).

\section{Resultados e discussão}

A gestão do cuidado e do trabalho em saúde obedece a racionalidades teórico-metodológicas produzidas a partir de um processo sócio histórico, em uma determinada época, que estabelece, para gestores, profissionais e usuários, formas de entender e intervir na saúde e na doença (TESSER; LUZ, 2008). Neste sentido, os discursos de gestores e profissionais foram organizados segundo as racionalidades e as motivações entendidas, respectivamente, como as lógicas e os impulsos que norteiam a gestão local do trabalho em saúde no território investigado.

Os discursos dos gestores e dos profissionais retratam o complexo contexto de vida local:

[...] uma dificuldade é a questão de que 50\%, $40 \%, 60 \%$ são palafitas [...] onde as pessoas jogam lixo ali mesmo onde moram, não têm facilidade de locomoção. Às vezes, tem cadeirantes, e aí tem toda uma série de dificuldades. (G1).

Diante deste panorama, os entrevistados reforçam que a população daquele território precisa de mais atenção, reconhecendo o valor da ESF para aquela comunidade: "[...] e dê graças a Deus por ter aparecido isso pr'a gente fazer, o PSF'! Pra toda a população! [...] Aqui é realmente uma coisa de fazer pena!" (PS1).

Este contexto de exclusão e de vulnerabilidade social ao qual a população está submetida é referido por Valla (2000, P. 43) como um "estado de emergência permanente", onde se verifica, invariavelmente, uma distribuição de serviços irregular, um difícil acesso aos serviços públicos e uma exposição às balas "perdidas". Certamente, esta situação pode ocasionar vários debates sobre a efetividade da ação em saúde, que demanda atuações de outras naturezas para além da assistência à saúde no seu restrito significado, e também coloca desafios aos gestores e aos profissionais da $\mathrm{AB}$, que necessitam de um planejamento local em médio e em longo prazo, como se verifica na fala de um gestor:

Aí você vê, na palafita, criança mexendo no esgoto. $O$ que a gente tem que trabalhar com a equipe é, assim, que isso sempre existiu. Evamos com calma, não dá pr'a gente mudar da noite pro dia, pro ideal que a gente acredita. Acho que tem
Programa Saúde da Família (PSF). 
que ter um planejamento local das ações, mas de uma forma mais flexível [...]. (G2).

Uma das racionalidades que pode ser apontada é explicitada pela fala de um gestor, que afirma que os profissionais de saúde, no cotidiano de trabalho em regiões com carências e graves problemas sociais de várias ordens, buscam respostas urgentes que atendam às necessidades mais imediatas daquelas populações: “[...] mas, como você tem, de certa forma, uma população muito carente [...] pequenas ações já surtem grande efeito e diferencial [...]" (G2).

Esta organização do trabalho em território de exclusão e vulnerabilidade social, estritamente relacionada à carência - privação de necessidades básicas, como por exemplo alimentação e moradia - e pautada em uma lógica emergencial, parece compor e/ou requerer profissionais que tratem bem e cuidem, impulsionados pela humildade:

[...] A carência é demais. Uma carência terrível. A primeira coisa que se tem que fazer para o pessoal, como tem aqui, é a humildade. Ser humilde, tratar bem o pessoal; ter muito cuidado com aquilo que você faz pra eles. Muito cuidado para a orientação, que é muito importante! (PS1).

Este relato parece reduzir a descrição e a reflexão sobre a assistência à população deste território a aspectos relacionais, que envolvem a humildade do profissional, o que nos remete ao senso comum da definição do humano como bondoso, humanitário, sensível à piedade, compassivo (BENEVIDES; PASSOS, 2005). É importante lembrar que esta atitude mais parcimoniosa pode funcionar como um tipo de defesa contra o medo, que parece impregnado na rotina desses profissionais. É comum, entre os profissionais, a ideia de que a USF seja um 'lugar de punição' para o trabalhador da saúde.

Além disso, a menção enfática da carência e da importância de orientar com parcimônia deixa subentendido que essa carência se articula, de certo modo, a uma possível forma de produzir o cuidado, que considera que a ignorância e a falta de informação são justificativas para definir o que se deve dizer e realizar, reduzindo as possibilidades, por exemplo, de entender os indivíduos como coparticipantes da construção do processo de cuidado e de ações para além das orientações.

Neste sentido, os relatos dos profissionais podem ilustrar práticas assistencialistas e motivações relacionadas à filantropia, distantes das discussões e da incorporação da humanização do cuidado como política pública de saúde, no que se refere à criação de cenários que alterem as formas de produção de saúde, com aumento da comunicação entre sujeitos e profissionais, associando a atenção à gestão e acolhendo o usuário como corresponsável da gestão compartilhada do cuidado (BENEVIDES; PASSOS, 2005; SHEIKHATTARI; KAMANGAR, 2010).

Também estão muito presentes nos discursos dos profissionais a banalização e a naturalização das situações de vulnerabilidade, diante da relação direta e mecânica entre a "pobreza absoluta" e as drogas: "Eu não tenho dificuldade porque a gente se acostuma [...] É o flagelo da droga que leva essas pessoas a essa pobreza absoluta" (PS3).

Além disso, há também a disseminação do uso de substâncias lícitas e ilícitas, como se vê no caso das drogas mais acessíveis em termos de preços: "[...] é uma droga muito barata. Tudo que é muito barato é presente. Cachaça é barato, é presente" (PS3).

Este discurso dialoga com estudos que associam o consumo de crack à experimentação de novas substâncias psicoativas, predominantemente por parte de população de baixo nível econômico, avançando pouco na reflexão sobre a complexidade do problema e o papel das forças locais no uso de substâncias ilícitas na comunidade e seus desdobramentos (RAUP; ADORNO, 2011).

Diante da complexidade dos problemas enfrentados, os gestores parecem reforçar a crença de que a agenda está pautada muito mais em problemas pontuais, que exigem 
respostas em curto prazo, do que em problemas que exigem uma perspectiva estratégica e uma ação planejada, ilustrando ações emergenciais, assistencialistas e pautadas na doença e na resolução de problemas agudos:

A gente não consegue... Atropelam! Os munícipes aqui atropelam! Então, a gente está redesenhando isso, pra fazer acontecer. $E$ isso, eu acho que vai facilitar a gestão, porque aí, cada um vai ter o seu papel, desenhado, definido. E a população começa a seguir e entrar no ritmo. (G4).

Várias questões poderiam ser aqui destacadas. Uma delas se relaciona ao fato de que não se consegue realizar a ação planejada porque os usuários dos serviços querem uma ação mais imediata e, às vezes, pontual, como, por exemplo: "A ACS não marcou a consulta pra ela [...] Ah, ninguém passou na minha casa" (G4).

Aqui fica evidente que a unidade de saúde tem encarado isto como um problema, carecendo de ações para enfrentar tal situação. Ainda assim, toda e qualquer nova ação a ser implementada deve ser definida pelos profissionais, cabendo à população adequar-se a ela ou 'entrar no ritmo', como explicita o depoimento da gestora local.

Há de se considerar, na discussão sobre a ação local, que os profissionais de saúde "não vivem a experiência da mesma maneira" que a população pobre (VALLA, 1998, P. 14). Seus projetos costumam ser anteriores ao contato com a população, ou seja, a proposta sanitarista pressupõe a "previsão" como categoria principal, pois a própria ideia de prevenção implica em um olhar para o futuro. Mas poderia ser levantada a hipótese de que esses setores da população conduzem suas vidas com a categoria principal de "provisão". Com isso, quer-se dizer que as lembranças da fome e das dificuldades de sobrevivência já enfrentadas levam seu olhar principal a se voltar para o passado e se preocupar em prover o dia de hoje. Uma ideia de acumulação, portanto. Assim, a proposta da previsão estaria em conflito direto com a da provisão (VALLA, 1998, P. 14).

Essa proposição aparece também em outros discursos que dizem respeito à distância que parece existir entre o que o gestor acredita ser o papel da USF no território e aquele que as pessoas esperam ver realizado (SILVA ET AL., 2013). Parece apontar para uma limitação do processo de trabalho, a fim de operar em alguma mudança de modelo técnico-assistencial em saúde, como se percebe na fala abaixo, de uma gestora que parece valorizar e dar destaque às ações de promoção da saúde:

Eles querem o médico para curar a dor de barriga [...] Elas não entendem que filtrar a água é necessário pra não se ter a dor de barriga! Então, é difícil a gente fazer a promoção... Então, PSF, é difícil a gente trabalhar aqui. (G4).

Para os gestores, os profissionais possuem um razoável autogoverno de seu processo de trabalho: "Mas é muito interessante o que acontece, eles não deixam parar, porque independe de quem está lá em cima. Lá, acontece" (G3).

Isto indica que, por um lado, a ação local não para, apesar de todos os obstáculos decorrentes das práticas da gestão pública, que, muitas vezes, são impeditivas; e, por outro lado, reforça, em suas práticas, tanto a racionalidade emergencial quanto a assistencialista, que atribuem aos usuários e resultam em um modelo assistencial pautado predominantemente em ações de tratamento.

Em contrapartida, os gestores reconhecem que o trabalho emergencial e mecanizado é fruto de um processo desafiador de consolidação da $\mathrm{AB}$ como ordenadora da assistência, permeado pelo desconhecimento do Sistema Único de Saúde (SUS) e do papel do profissional no sistema (SILVA ET AL., 2013). Além disso, é caracterizado pela consequente sobrecarga de demandas para os níveis secundário e terciário de atenção, como se vê na fala a seguir: 
Acho que, primeiro, todos os profissionais precisam entender muito bem isso, porque, às vezes, a gente, um funcionário lá na ponta, que ele não sabe nem o que é SUS, ele não reconhece nem o seu papel diante do sistema [...] A gente vai diminuir, lá, a especialidade, porque aí a gente fortalece a Atenção Básica e o indivíduo vai precisar menos de hospitalização da complexidade alta, da alta complexidade. (G3).

Neste sentido, os gestores reconhecem insuficiências na estrutura organizacional da AB e na gestão:

A gente não tem todos os serviços básicos que precisaria ter numa unidade, na porta, lá [...] se o gestor não tiver o conhecimento disso e levar à sua equipe, se não direcionar, essas palavras vão ficar em vão. (G3).

Tais insuficiências parecem ter um impacto direto na função do nível primário de atenção como ordenador do cuidado em saúde. Um dos gestores aponta a indissociabilidade entre gestão e atenção à saúde, valorizando a implicação dos diferentes sujeitos - usuários, trabalhadores e gestores - no processo de produção de saúde, diretriz preconizada pelo Ministério da Saúde e um dos desafios para o município.

Então, essa linha de cuidado, acho que tem que trabalhar muito no dia a dia e, pra nós, da gestão, fica cada vez mais claro que esta construção a gente tem que trazer... Porque não adianta falar, enquanto gerente, que isso é importante, e ficar na enfermagem. Você tem que estar junto e ajudando a construir esse processo. (G2).

Chama a atenção que as críticas contundentes feitas pelos gestores sobre seu próprio processo de trabalho estão centradas muito mais na 'falta' do que em ações propositivas ou expressas como positividades. Desponta, também, uma dificuldade para analisar e relacionar a prática da gestão pública em saúde, as demandas e necessidades, bem como os caminhos para dar respostas mais adequadas àquela população local.

É importante ressaltar o planejamento na gestão em saúde, pertinente a aspectos voltados ao campo relacional, especialmente dos profissionais de saúde. Nesse caso, parece que o gestor está se referindo muito mais à relação do profissional com a população do que entre a equipe de saúde.

Quando um sujeito diz que "temos que pensar em ações de cuidar do cuidador", ele chama a atenção para um tema recorrente na área de saúde, na qual muitos profissionais sentem-se desamparados ao lidar com processos que produzem marcas e efeitos muito significativos para suas vidas:

[...] gerir, desse ponto de vista, é pensar mais nas questões psicológicas dos profissionais do que no planejamento somente de ações de saúde para a população. Temos que pensar em ações de cuidar do cuidador mesmo, porque, assim, às vezes, a gente foca muito na população e os profissionais acabam adoecendo... (G2).

Esta fala, preocupada com as "questões psicológicas” dos profissionais, dialoga com uma das pautas prioritárias da gestão do trabalho em saúde, diante da frequente insatisfação dos profissionais quanto à diminuição da autonomia; ao aumento da pressão, tanto por parte das chefias quanto dos pacientes; ao excesso de tarefas burocráticas; ao pouco reconhecimento social: às condições inadequadas de trabalho; e aos baixos salários (ASSUNÇÃO ET AL., 2012).

Neste sentido, compreender a trajetória e a inserção de um profissional significa entender valores e aspectos que dão sentido à vida. As entrevistas apontaram que os gestores e os profissionais de saúde têm distintas formações e diferentes inserções na área da saúde. Ao resgatar suas inserções iniciais na saúde, pode-se observar que suas trajetórias expressam uma diversidade de motivações, propósitos e posições. Mas apresentam, sobretudo, singularidades recortadas por 
processos sociais mais amplos, alguns deles intimamente relacionados à organização dos serviços de saúde na cidade.

Ao relatar sua trajetória profissional, a médica da USF destaca com orgulho sua infância pobre no Nordeste e seu difícil percurso até se tornar uma profissional de saúde. Há 40 anos atuando no município, ela relata o amor que tem à profissão e afirma que, mesmo sendo aposentada, não pretende parar de trabalhar. Impregnado de simbologia religiosa, seu discurso se utiliza de termos ainda muito presentes nos imaginários da população e do profissional médico, como 'amor' e 'caridade', e, de certa forma, reafirma o 'compromisso com a pobreza'. Assim, sua visão do que é ser médico(a) está intimamente associada ao assistencialismo e à filantropia. Porém, pode-se considerar que, quando ela usa a expressão "divido com todo mundo", está também apontando aspirações de caráter humanístico.

[...] e ai daquele médico que realmente não tiver o espírito de caridade. Não quero dizer que eu sou tão caridosa, mas, dentro do meu alcance, eu faço. Dentro das possibilidades que eu tenho, de fazer, eu faço! (PS1).

A origem pobre da profissional parece legitimar um discurso marcado pela vocação e pela devoção ao trabalho, marcando a filantropia como uma de suas motivações. Como refere Lalande (1999, P. 1224):

todo problema da vocação consiste, pois, em saber qual a distinção que devo fazer entre a própria essência que Deus me propõe e que está sempre no meu fundo como a sua melhor parte, e é, por assim dizer, a parte, a parte ideal de mim mesmo, é a própria essência que realizo e de que consigo tomar uma posse efetiva.

Mas a vocação é um "conceito pedagógico" e se diferencia da aptidão. A primeira significa "propensão para qualquer ocupação, profissão ou atividade", e a segunda pressupõe a "atração que um indivíduo sente para uma determinada forma de atividade". Em suma, a "aptidão pode ser controlada objetivamente e a vocação é subjetiva" (ABBAGNANO, 2007, P. 1007).

Em regiões de grande vulnerabilidade, algumas áreas profissionais revestem-se de grande importância, como destaca um profissional da área de serviço social entrevistado, que atua no município há mais de 30 anos. As mudanças ocorridas na administração municipal, em relação à política de assistência social, foram acompanhadas de perto por ele, o que, em sua opinião, permitiu que o mesmo tivesse "experiência de trabalho em várias comunidades do município". Com a implantação da nova política que instituiu o Sistema Único de Assistência Social (Suas), significativas transformações foram implementadas. Tais alterações parecem relacionar-se com as mudanças ocorridas nos últimos anos, em relação às práticas do serviço social no âmbito comunitário, que passaram a priorizar as situações e os casos dos territórios, e a enfrentar a enraizada cultura assistencialista e paternalista que sempre permeou suas práticas.

Ainda segundo este profissional, seus companheiros de profissão realizam o atendimento à população menos favorecida e, por isso, são deslocados para os bairros periféricos das cidades. Ele ainda destaca a importância do papel do assistente social na USF e como tal profissional se tornou uma referência importante para a população da comunidade, desde o "nascimento de uma criança até o falecimento". Seu discurso parece reforçar o valor que a população dá a esses profissionais, exatamente pelo significado da ação assistencialista que empreendem na comunidade.

Cotidianamente em contato com conflitos, situações de marginalização e sofrimento, o trabalho pode ser considerado:

[...] penoso, é árduo, porque você lida com amarguras, conflitos, decepções, com pessoas que 
vieram do Nordeste, pensando que chegariam aqui e teriam casa própria; porque a televisão só mostra o lado bonito... A área social ainda é a área menos favorecida nesse país... (PS3).

Este depoimento mostra como os trabalhadores que atuam junto ao social compõem um campo profissional que se ocupa dos diferentes problemas que emergem a partir do aumento populacional das cidades e da dificuldade de administrá-los.

A trajetória de alguns gestores mostra como as mudanças ocorridas nos últimos anos trouxeram possibilidades e interesses por uma nova inserção profissional, mesmo para aqueles que começaram a atuar na área sem formação superior, como é o caso de dois gestores que assumiram seus cargos após terem sido profissionais de áreas técnicas, que exigiam apenas a formação de nível médio.

Outra usual mudança de trajetória dos profissionais de saúde se dá em relação aos níveis de atenção, nesse caso, do hospital para a $\mathrm{AB}$, como se vê na fala abaixo:

Eu me formei e dezembro de 1984, eu sou enfermeira. Logo que saí da faculdade, fui trabalhar na Santa Casa... Eu recebi um convite para abrir uma UTI aqui [... A Aí, com dez anos de UTI, senti a necessidade de que bastava UTI. Era desgastante emocionalmente, e aí, eu recebi o convite para ir pra Atenção Básica. Eles insistiram no convite e eu tinha uma resistência, mas, por fim, num acordo, fui trabalhar numa unidade básica... (G3).

Ainda que a gestora utilize a expressão "eu tinha uma resistência", ela declara que o trabalho no hospital era "desgastante emocionalmente". Aqui fica explicitada, também, uma visão muito presente entre os profissionais e a própria população, na qual a atenção primária (aqui denominada $\mathrm{AB}$ ) reforça uma concepção de algo simples, menos compleхо: "interpreta-se primário como primitivo" e, por isso, muito menos desgastante, e encarado como motivação pelo profissional.
Essa visão básica da Atenção Primária à Saúde faz com que ela possa ser feita de qualquer jeito: com pouco financiamento, com relações de trabalho extremamente precarizadas, com um arsenal de medicamentos muito estrito, com uma infraestrutura física completamente deteriorada, na ausência de sistemas eficazes de Educação Permanente. (MENDES, 2005, P. 218).

Esta visão pode ser reforçada pelo ambiente e pela organização do trabalho, especialmente, no setor terciário de saúde, com características geradoras de doenças, absenteísmo e dificuldades no cotidiano de trabalho, como o sistema de turnos, os riscos biológicos, físicos e químicos, bem como a sobrecarga física e emocional decorrente das ações de cuidado, conforme descrito por Sala e Parreira (2011).

As formas de contratação dos profissionais aparecem também como elementos determinantes do cuidado em saúde. Chama a atenção o fato de um dos gestores ter mencionado seu forte vínculo com a comunidade do bairro, embora já não fosse mais profissional da prefeitura do município. $\mathrm{O}$ discurso ambíguo revela que, apesar de se sentir mais realizado no serviço público, ele teria aprendido mais em uma empresa estatal que possuísse outras formas de contratação. Seu objetivo, de acordo com seu depoimento, seria o de aprender mais e "voltar a atuar no bairro". Esta afirmação mostra, em primeiro lugar, que os conhecimentos e as habilidades adquiridos com os processos de trabalho na empresa são distintos, e podem trazer alguns ganhos para o serviço público. Ou seja, de algum modo, expressa diferentes lógicas entre a gestão, mas essas não estão atreladas aos seus objetivos, e sim aos meios para atingi-los. Por outro lado, aponta certa idealização de que somente no setor público ele, de fato, se realizará enquanto profissional e cidadão: "Eu gosto mais desta parte, de lidar com as pessoas, de ajudar. Eu me sinto mais útil enquanto cidadão" (G1). 
Sua opção pela empresa é explicitamente relatada como decorrente de benefícios que tem como trabalhador aprovado em concurso. O discurso aponta, também, a fragilidade do vínculo de trabalho, pois a condição de 'estar chefe' pode deixar de valer a qualquer momento:

Eu não podia dizer não, porque tem uma série de benefícios. [...] Enquanto você está chefe de uma unidade de saúde, você está chefe, você tem que ganhar mais por isso, está naquela responsabilidade. No dia seguinte, você pode não estar chefe e voltar a ganhar o que você ganhava antes. Então, naquele momento, era a melhor opção pra mim, apesar de eu não querer. (G1).

Outra profissional destaca que se inseriu na área da saúde no município porque soube que precisavam de psicólogo na rede. A profissional afirma que, mesmo sem saber, os psicólogos daquela instituição já estavam sendo selecionados para trabalhar na secretaria de saúde, na área de saúde mental. Não houve, portanto, um concurso público, mas uma seleção entre os profissionais que já atuavam na prefeitura: "Nós fomos convidados para participar de algumas oficinas dentro da saúde mental e estávamos sendo selecionados sem ter noção de que estávamos sendo...”(PS2).

Parece ter ocorrido uma série de arranjos administrativos no município, para dar conta de necessidades que vinham surgindo a partir da organização dos serviços de saúde. Esse fato gera muitos problemas até os dias de hoje, uma vez que uma parcela dos profissionais faz parte da administração pública, e a outra, vem sendo contratada por parceiras, Organizações Sociais (OS) ou Organizações da Sociedade Civil de Interesse Público (Oscip).

A questão da flexibilização do vínculo de trabalho (terceirizações e cooperativas) que vem se dando no município acompanha as mudanças sofridas no mundo do trabalho e estão muito presentes na esfera da administração pública brasileira, particularmente no setor saúde.
O estudo de Sano e Abrucio (2008) mostra como o modelo da Nova Gestão Pública (NGP) espalhou-se pelo mundo com a promessa de atacar dois males burocráticos: o excesso de procedimentos e a baixa responsabilização dos burocratas frente ao sistema político e à sociedade. A proposta básica foi a de flexibilizar a administração pública e aumentar a $a c$ countability com uma nova forma de provisão dos serviços, baseada na criação de entidades públicas não estatais como as OS. No Brasil, a experiência reformista inicia-se em 1995, com as ideias do Plano Diretor da Reforma do Aparelho do Estado. A área da saúde no município de São Paulo (SP) constituiu-se em um campo paradigmático para avaliar a implantação da NGP no Brasil.

Nos anos seguintes, vários municípios adotaram a mesma lógica de contratação e gestão na área da saúde, o que aumentou consideravelmente a contratação de profissionais de saúde por meio de mecanismos de terceirização e outras modalidades de contratos informais para a inserção de trabalhadores no sistema de saúde. A justificativa para a utilização de tais mecanismos tem amparo na premissa de que esses fortaleceriam a governabilidade e melhorariam a qualidade da assistência nas unidades de saúde, uma vez que não haveria mais problemas com a falta e a reposição de pessoal nos serviços (VARELLA; PIERANTON, 2008). Outra razão para a contratação por meio de terceirização parte das exigências legais concernentes aos Artigos 18 e 19 da Lei de Responsabilidade Fiscal, que definem e limitam as despesas com pessoal para cada ente da Federação, que não podem exceder $50 \%$ da receita da União e $60 \%$ das receitas para Estados e Municípios (BRASIL, 2000).

O que se depreende de estudos da agenda público-privada nessa nova modalidade de gestão para os serviços de saúde é que a gestão de serviços, a formulação e o controle da política são de responsabilidade da esfera estatal, enquanto o processo de trabalho e o gerenciamento de recursos humanos cabem à esfera privada. 
Isto possibilita uma lógica para o manejo dos recursos humanos em que se distingue o controle direto sobre o trabalhador e o trabalho. No entanto, questão central encontra-se na capacidade do Poder Público se fazer presente na implementação dessa modalidade de gestão no âmbito local, retendo e ampliando os espaços de formulação política, garantindo a equidade no acesso aos serviços de saúde e contemplando o controle público, de modo a observar a defesa da justiça social como meta prioritária de sua atuação. (CARNEIRO JUNIOR; ELIAS, 2006, P. 920).

Embora o tema da contratação de profissionais esteja pouco presente nos discursos dos gestores, observamos vários problemas decorrentes de finalizações de contratos especialmente, de ACS - e das incertezas em relação ao futuro profissional em uma USF.

O que se depreende desse processo é que não pode escapar dos efeitos da sistemática precarização dos vínculos de trabalho na área de saúde. Resta, ainda, investigar como essa multiplicidade de vínculos compromete a organização do trabalho e impacta na consolidação democrática do sistema público de saúde.

\section{Considerações finais}

Diante de um território de elevada vulnerabilidade, o cuidado prestado à população parece obedecer a racionalidades que convergem para o assistencialismo, em ações emergenciais voltadas à resolução imediata de problemas agudos a partir da lógica queixa-diagnóstico-conduta, reforçando o modelo assistencial pautado predominantemente em ações de tratamento. Se, por um lado, os gestores e profissionais reconhecem a importância da ESF no território, e a $\mathrm{AB}$ como ordenadora do cuidado, por outro, banalizam e naturalizam os problemas de saúde na medida em que os atrelam à pobreza extrema.

Os sujeitos parecem ser motivados pela filantropia, em um cotidiano que busca oferecer respostas em curto prazo, permeado pela vocação e pela devoção dos profissionais. Por outro lado, a fragilidade do vínculo de trabalho, tanto na posição de chefia quanto na forma de contratação, traz insegurança aos profissionais, motivando-os a novos horizontes na carreira, distantes do SUS.

Resta-nos indagar se essas motivações dos profissionais e as racionalidades produzidas por suas intervenções serão capazes e suficientes para captar as diversas dinâmicas engendradas no território da Vila dos Pescadores, em Cubatão (SP), de modo a valorizar aquele espaço público como local de sobrevivência, mas também de mudanças, e, portanto, com potencialidades de transformações futuras.

\section{Referências}

ABBAGNANO, N. Dicionário de Filosofia. 5. ed. São Paulo: Martins Fontes, 2007.

ASSUNÇÃO, A. A.; MACHADO, A. F.; ARAUJO, T. M. Vulnerabilidades ocupacionais e percepção de saúde em trabalhadores do SUS. Revista Brasileira de Estudos de Populações, São Paulo, v. 29, n. 1, p. 147-167, 2012.
BAUMAN, Z. Confiança e medo na cidade. Rio de Janeiro: Zahar, 2009.

BENEVIDES, R.; PASSOS, E. A humanização como dimensão pública das políticas públicas de saúde. Ciência \&t Saúde Coletiva, Rio de Janeiro, v. 10, n. 3, p. 561-571, 2005. 
BRASIL. Lei complementar $n^{\circ} 101$, de 04 de maio de 2000. Estabelece normas de finanças públicas voltadas para a responsabilidade na gestão fiscal e dá outras providências. 2000. Disponível em: <http://www.planalto.gov.br/ccivil_03/leis/lcp/lcp101.htm>. Acesso em: 9 jan. 2015.

BUSS, P. M.; PELLEGRINI FILHO, A. A saúde e seus determinantes. Physis: Revista de Saúde Coletiva, Rio de Janeiro, v. 17, n. 1, p. 77-93, 2007.

CARNEIRO JUNIOR, N.; ELIAS, P. E. M. Equidade no acesso a hospitais públicos. Revista de Saúde Pública, São Paulo, v. 40, n. 5, p. 914-920, 2006.

FRAGA, A. B. et al. Curso de extensão em promoção da saúde para gestores do SUS com enfoque no Programa Academia da Saúde. Brasília, DF: Ministério da Saúde, Secretaria de Vigilância em Saúde: Fundação Universidade de Brasília: CEAD, 2013.

GONZALES-REY, F; MORI, V. Reflexões sobre o social e o individual na experiência do câncer. Psicologia $\mathcal{E}$ Sociedade, Florianópolis, v. 23, n. spe., p. 99-108, 2011.

KOGA, D. Medidas de cidades: entre território de vida e territórios vividos. São Paulo, Cortez, 2003.

LALANDE, A. Vocabulário técnico e crítico da Filosofia. São Paulo: Martins Fontes, 1999

MENDES, E. V. Entrevista - O SUS e a Atenção Primária à Saúde. Revista de APS, Juiz de Fora, v. 8, n. 2, p. 218-219, 2005.

ORGANIZAÇÃO MUNDIAL DA SAÚDE (OMS). Conferência Mundial sobre os Determinantes Sociais da Saúde. Diminuindo as diferenças: a prática das políticas sobre os determinantes sociais de saúde. Documento para discussão. Rio de Janeiro, 2011. Disponível em: <http://www.who.int/sdhconference/ discussion_paper/Discussion_Paper_PT.pdf $>$. Acesso em: 9 jan. 2015.

RAUP, L.; ADORNO, R. Jovens em situação de rua e os usos do crack: um estudo etnográfico em duas cidades. Revista Brasileira de Adolescência e Conflitualidade, São
Paulo, n. 4, p. 52-67, 2011.

SALA, A.; PEREIRA, S. M. C. P. O trabalho no setor hospitalar: adoecimento e afastamento por motivos de saúde. In: ASSUNÇÃO, A. A.; BRITO, J. (Org.).

Trabalhar na saúde: experiências cotidianas e desafios para a gestão do trabalho e do emprego. Rio de Janeiro: Fiocruz, 2011.

SANO, H.; ABRUCIO, F. L. Promessas e resultados da nova gestão pública no Brasil: o caso das organizações sociais de saúde em São Paulo. Revista de Administração de Empresas, São Paulo, v. 48, n. 3, p. 64-80, 2008.

SHEIKHATTARI, P.; KAMANGAR, F. How can primary health system and community -Based participatory research be complementary? International Journal of Preventive Medicine, Filadélfia, v. 1, n. 1, p. 1-10, 2010.

SILVA, L. A.; CASSOTTI, C. A.; CHAVES, S. C. L. A produção científica brasileira sobre a Estratégia Saúde da Família e a mudança no modelo de atenção. Ciência e Saúde Coletiva, Rio de Janeiro, v. 18, n. 1, p. 221-232, 2013

SOLAR, O.; IRWIN, A. A conceptual framework for action on the social determinants of health: social determinants of health discussion paper 2 (policy and practice). [Internet]. Geneva: World Health Organization, 2010. Disponível em: <http://whqlibdoc.who.int/publications/2010/9789241500852_eng.pdf >. Acesso em: 10 nov. 2012.

SOUZA, M. L. Mudar a cidade: uma introdução crítica ao planejamento e à gestão urbanos. 7. ed. Rio de Janeiro: Bertrand Brasil, 2010.

TESSER, C. D.; LUZ, M. T. Racionalidade médicas e integralidade. Ciência \&t Saúde Coletiva, Rio de Janeiro, v. 13, n. 1, p. 195-206, 2008.

THOMPSON, J. B. Ideologia e cultura moderna. Petrópolis: Vozes, 1995

VALLA, V. V. Redes sociais, poder y saúde à luz das classes populares em um contexto de crise. Interface 
- Comunicação, Saúde, Educação, Botucatu, v. 4, n. 7, p. 37-56, 2000.

Sobre participação popular: uma questão de perspectiva. Cadernos de Saúde Pública, Rio de Janeiro, v. 14, supl. 2, p. 7-18, 1998.

VARELLA, T. C; PIERANTON, C. R. Mercado de trabalho: revendo conceitos e aproximando o campo da saúde. A década de 90 em destaque. Physis: Revista de Saúde Coletiva, Rio de Janeiro, v. 18, n. 3, p. 521-544, 2008.
VERAS, M. Cidade, vulnerabilidade e território. Pontoe-Vírgula, São Paulo, n. 7, p. 32-48, 2010.

Recebido para publicação em julho de 2014

Versão final em janeiro de 2015

Conflito de interesses: inexistente

Suporte financeiro: CNPq - Edital MCT/CNPq 14/2011 (processo

475298/2011-0 